\title{
MULHERES, DIVINDADES, PROSTITUIÇÃO SAGRADA E RELIGIÃO 1RS 11, 1-13: LEITURAS DESDE A HERMENÊUTICA NEGRA E FEMINISTA
}

\author{
Maricel Mena López*
}

\section{RESUMO}

A narrativa de 1 Rs 11,1-13 culpabiliza as mulheres por terem desviado o coração do rei Salomão, sendo elas as responsáveis diretas pela grande apostasia do rei. Assim, os excessos no seu governo, evidentes nas suas construções majestosas, no seu número elevado de mulheres, na implementação da corveia, dos impostos, do empobrecimento das minorias, do enriquecimento das elites e sua incapacidade de governar com justiça e retidão ficam relegados a um segundo plano. As mulheres, que tinham um papel fundamental como mediadoras entre os deuses e a comunidade, foram estereotipadas com as metáforas de idolatria e prostituição. Desta forma, este artigo pretende fazer uma leitura libertadora das práticas femininas do século $X$, bem como desmascarar os mecanismos sutis dos textos patriarcais que suplantam o poder feminino pelo dos varões circuncisos.

Palavras chave: 1 Reis; divindades; prostituição; idolatria; mulher e religião; hermenêutica negra.

\section{WOMEN, DEITIES, SACRED PROSTITUTION AND RELIGION 1 KINGS 11, 1-13: READINGS FROM A BLACK AND FEMINIST HERMENEUTICS}

\section{ABSTRACT}

The narrative of 1 Kings 11:1-13 blames women for having led astray the heart of the King Solomon, and they are directly responsible for the king's great apostasy. Thus, the excesses in his government, evident in his majestic constructions, in his high number of women,

* Professora na Faculdade de Teologia da Universidad Santo Tomás. Pós-doutorado em Hermenêutica Feminista Latino-Americana na Escola Superior de Teologia (EST). Doutora em Ciências da Religião na Universidade Metodista de São Paulo (UMESP). ORCID: https://orcid.org/oooo0001-5958-0570. E-mail: maricelmena@usantotomas.edu.co. 
in the implementation of corvee, taxes, the impoverishment of minorities, the enrichment of elites and his inability to govern with justice and rectitude, are relegated to a background. Women, who played a fundamental role as mediators between the gods and the community, were stereotyped with the metaphors of idolatry and prostitution. So, this article intends to make a liberating reading of the feminine practices of the 10th century, as well as to unmask the subtle mechanisms of the patriarchal texts that supplant the feminine power with that of the circumcised men.

Keywords: 1 Kings; deities; prostitution; idolatry; woman and religion; black hermeneutics.

\section{MUJERES, DEIDADES, SAGRADA PROSTITUCIÓN Y RELIGIÓN 1RS 11, 1-13: LECTURAS DE LA HERMENEUTICA NEGRA Y FEMINISTA}

\section{RESUMÉN}

La narración de 1 Reyes 11: 1-13 culpa a las mujeres por haberse descarriado del corazón del rey Salomón, y ellas son directamente responsables de la gran apostasía del rey. Así, los excesos en su gobierno, evidentes en sus majestuosas construcciones, en su elevado número de mujeres, en la implementación de la corbeta, los impuestos, el empobrecimiento de las minorías, el enriquecimiento de las élites y su incapacidad para gobernar con justicia y rectitud, son relegado a un segundo plano. Las mujeres, que jugaron un papel fundamental como mediadoras entre los dioses y la comunidad, fueron estereotipadas con las metáforas de la idolatría y la prostitución. De esta manera, este artículo pretende hacer una lectura liberadora de las prácticas femeninas del siglo X, así como desenmascarar los sutiles mecanismos de los textos patriarcales que suplantan el poder femenino por el de los hombres circuncidados.

Palabras clave: 1 Reyes; deidades; prostitución; idolatría; mujer y religión; hermenéutica negra.

\section{INTRODUÇÃO}

Neste estudo pretendo questionar o processo de hierarquização das religiões e especialmente do monoteísmo e fundamentalismo religioso israelita que culpabilizou as mulheres e suas divindades dos abusos de poder do rei Salomão. Ao desvelar esses abusos contra as mulheres cananeias e sua religião, quero fazer jus à história humana 
que se constrói nos contornos da oficialidade. Assim sendo, quero ainda resgatar o simbolismo das Deusas em suas dimensões política e psicológica, significativas para o movimento feminista que questiona a centralização da experiência espiritual num Deus único e masculino.

As diversas divindades presentes na história de Israel e de Judá têm sido exploradas principalmente a partir de pesquisas arqueológicas. As descobertas de Kuntillet Ajrud e Khirbet el-Qom são importantes para a reconstrução do Israel monárquico do século VIII a.C. (Israel FINKELSTEIN, 2015), onde a deusa Asherá adquire um rol importante.

Diversas descobertas arqueológicas em túmulos e casas particulares de importantes cidades de Israel dos séculos VIII-VII a.C., mostram estatuetas-postes que retratam a figura feminina. Nelas os seios são destacados e sustentados pelas mãos e, possivelmente, representam a deusa Asherá. Em Israel as divindades femininas mais presentes no cenário religioso eram Isherá e Ishtar. No Israel Antigo, não apenas as mulheres serviam as divindades femininas, mas, por vezes, toda a família. As deusas-mães Asherah e Ishtar, de origem cananéia e babilônica, eram as mais cultuadas (Fydel SANTIAGO, 2017, p. 71).

As descobertas de materiais ugaríticos constatam a existência de numerosos pilares femininos do oitavo século, especialmente em Judá. Isto levou a sustentar a tese básica de que a Deusa Asherá teria trabaIhado em consórcio com Javé em Israel e Judá durante o período da monarquia israelita (Judith HADLEY, 1994). Contudo, o trabalho desta e outras deidades como Astarte foi condenado nos mesmos textos bíblicos ainda fazendo parte da religião popular e tradicional israelita. Porém, como adverte Sue'Hellen Matos, "A religião da família é incrivelmente tenaz, ela pode sobreviver inclusive a insistentes estratégias oficiais para reprimi-la. Ela se adaptava às circunstâncias histórico-religiosas do contexto maior sem que seu cerne fosse por elas afetado" (Sue'Hellen MATOS, 2019, p. 354).

Tendo em vista esse processo de adaptabilidade e resistência, inicio este ensaio com uma discussão preliminar sobre a religião das deusas para, em seguida, estudar a narrativa de Rs 11,1-13 com especial atenção à exploração de duas deidades femininas mencionadas em 1Rs 11, 1-13, prestando atenção à linguagem patriarcal que as culpabilizou da apos- 
tasia de Salomão, para finalmente, apresentar algumas considerações conclusivas do estudo.

\section{RELIGIÃO DAS DEUSAS: INÍCIO DE DISCUSSÃO}

As pesquisas arqueológicas têm revelado que, no Antigo Oriente Próximo, a mais antiga imagem humana do divino era feminina. Desde a época paleolítica até a neolítica, e estendendo-se aos inícios da civilização antiga, encontramos a imagem da Deusa, amplamente difundida, sem uma figura masculina que a acompanhasse (Marija GIMBUTAS, 1996). Edwin O. James afirmou que "o culto da mãe-Deusa deve ser efetivamente uma das religiões mais velhas e que mais tempo sobreviveu no mundo antigo" (Edwin O. JAMES, 1960, p. 24). Esta Deusa era considerada como a Matriz Fundamental, o grande útero dentro do qual são geradas todas as coisas: deuses e humanos, céu e terra, seres humanos e não humanos (Rosemary RUETHER, 1993).

As teorias sobre a origem da Deusa no período paleolítico superior se fundamentam na justaposição de hábitos de parentesco materno com adoração de antepassados. A primeira evidência se fundamenta no estudo das sociedades matrilineares. Segundo James Frazer e Margaret Mead (1935) e outros estudos antropológicos, nas mais antigas sociedades humanas as pessoas não tinham a compreensão da relação entre sexo e reprodução. Deste modo, não podia ser compreendido o conceito de paternidade. A mãe era vista como a única origem da família e, por isso, os filhos tomavam o nome do clã da mãe. A esta estrutura se lhe dá o nome de matrilinear.

A segunda teoria se relaciona com o início das crenças e rituais religiosos e sua conexão com a descendência matrilinear. Nestas sociedades onde a mãe pode ser a única origem da família, a adoração aos antepassados era a base do ritual sagrado, e os relatos ancestrais se relacionam através da matrilinearidade. Isto é, que o conceito de criador da vida humana é formulado a partir da imagem da mulher. A terceira evidência e a mais tangível provem das inúmeras esculturas de mulheres encontradas nas culturas do paleolítico superior, algumas delas datando de 25.000 a.C. 
As esculturas do período paleolítico e aquelas dos períodos neolíticos são similares em questão de materiais, tamanho e estilo. Jacketta Hawkes (1958) comentou a relação entre os dois períodos, destacando que as figuras femininas paleolíticas se parecem extraordinariamente às Deusas Mãe ou Terra dos povos agrícolas de Eurásia na era neolítica, e devem ser ancestrais diretos delas. No lugar hoje conhecido como Jericó (em Canaã), há cerca de 7000 anos a.C., foram encontradas figuras femininas de argila com as mãos no peito semelhante à Deusa Mãe que mais tarde foram disseminadas amplamente no Antigo Oriente (Merlin STONE, 1994).

Desde o ingresso a Canaã ou Palestina, ano 1230 a.C., até o final do reino de Judá temos um extenso período de cerca de seiscentos anos, os mais ricos e interessantes da história bíblica, que foram definitivos para plasmar a cultura bíblica e que teriam especial repercussão para a reconstrução da vida das mulheres em Israel.

A principal característica deste período da história israelita foi o sincretismo, ou fusão, entre o culto javista e os cultos cananeus. As tribos seminômades vieram de uma longa marcha pelo deserto onde lhes foi revelado um Deus sumamente espiritual e único para todo o povo hebreu, com características masculinas, com um alto grau de moral em comparação com os povos vizinhos e um culto relativamente simples, apenas desenhado, sem imagens nem templo.

Ingressando em Canaã se encontraram com uma cultura riquíssima em suas expressões, mas fundamentalmente uma cultura agrária e sedentária, com cidades fortificadas, com reis e corte, com templos, sacerdotes, colégios de profetas e adivinhos e, sobretudo, com um culto à fertilidade.

O conceito do Deus único era relativamente incipiente e contraditório ao mundo cultural de onde vieram - Egito - e aonde chegaram, Canaã. Por outro lado, não tinham suficiente consciência do conceito monoteísta (Haroldo REIMER, 2008). Tratava-se de um monoteísmo henoteísta, ou seja, de um deus para uma raça ou povo, sem negar a existência de outros deuses. Tudo isso explica o fato de que, por longos séculos, o monoteísmo não lograra afirmar-se definitivamente apesar do esforço dos profetas e de outros dirigentes espirituais. Somente 
após o exílio babilônico, o javismo começa a circular sem a ameaça de deuses estrangeiros.

Sendo agrária a cultura cananeia, as chuvas eram importantes, pois delas dependia a fertilidade da terra. A seca significava, literalmente, a morte. Por isso, a maioria dos cultos giram em torno da fertilidade, que dependia do princípio feminino. As Deusas femininas, mais antigas do que os Deuses masculinos, representavam a vida que surge da terra e do seio da mulher. Elas são a semente original, a força oculta e misteriosa da natureza que brota na primavera, após as primeiras chuvas.

As antigas civilizações urbanas da Suméria, Babilônia, Egito e Canaã continuam usando a imagem feminina do divino, porém, emparelhada com uma divindade masculina. As mitologias conhecem infinidades de casais divinos. Em Canaã, além de El e Asherá, os mais populares eram Baal e Astarte. Para os cananeus, a fertilidade e a sexualidade não são somente sagradas, senão divinas. É a mesma vida das Deusas e Deuses. Por isso, os templos cananeus e os santuários esparzidos por toda Palestina, especialmente nos lugares altos, tinham mulheres e homens para o exercício da prostituição sagrada.

A "prostituição sagrada" ou sexo ritualístico seria uma prática ligada à religião, na qual mulheres comuns e sacerdotisas (as "prostitutas sagradas") teriam relações sexuais com quem as procurasse com objetivo de ser abençoado com fertilidade, seja para si, esposa, terras ou animais. Por essas relações sexuais, elas receberiam um pagamento, porém o pagamento seria oferecido à divindade ou ao templo (Keila BATISTA, 2011, p. 190).

Perante a monarquia, esses elementos cultuais cananeus estavam muito acentuados. O mesmo Salomão oferece sacrifícios no lugar alto de Gibeon (1Rs, 3, 4-15). É interessante salientar aqui que esse culto, inicialmente foi praticado pelo povo, passa aqui por um processo de hierarquização. A relação sexual que era necessária para que a natureza fosse fértil, agora é centralizada no monarca que possui um harém numeroso. "Os haréns eram constituídos por mulheres de diversas origens, que serviam de relacionamento do rei com as principais famílias de seu reino e com outras dinastias ao seu redor" (Xabier PICAZA, 2013, p. 163). 
O grande número de mulheres dentro do harém era um símbolo de abundância, riqueza e virilidade do rei, uma vez que a força sexual era considerada sinal de bênção para o reino. O harém de Salomão contava com muitas mulheres estrangeiras representantes de nações com as que se haviam estabelecido relações cordiais de diplomacia e pacto. Entregar uma mulher a um rei era um símbolo de pacto territorial, de fim da guerra e disputas e do início de uma nova etapa de paz entre esses povos e nações. $O$ rei que tinha esposas, princesas e concubinas estrangeiras, tinha que respeitar as crenças religiosas dessas mulheres para manter a cordialidade, a tranquilidade e a harmonia familiar, por isso, se construíram lugares de adoração de seus deuses e deusas.

Não obstante, o harém passou a ser um símbolo da prostituição e, por isso, uma instituição que vai contra o querer de Javé, segundo os autores deuteronomistas encarregados de escrever essa história. $O$ rei, que em princípio mantinha relação somente com a sacerdotisa principal como metáfora do matrimônio sagrado com a mesma divindade, agora é a personificação viril da divindade monoteísta. Assim, justifica-se sua poligamia e a submissão das mulheres como mandato e símbolo do poder divino. O Deus masculino dos israelitas se apresenta como modelo que justifica o esquema de domínio, como bem aponta Judith Plaskow:

O Deus como regra e rei do universo é o pináculo de uma vasta hierarquia que se estende desde o próprio Deus até homens, mulheres, crianças, animais e finalmente à terra como regra hierárquica, Deus é o esquema de domínio que os seres humanos criam para si. Como rei santo, ele escolhe a Israel como seu santo povo. Como santo guerreiro, ele sanciona a destruição de outros povos. Como santo legislador, ele ordena a subordinação de mulheres na comunidade judaica. (Judith PLASKOW, 1991, p. 132).

Contudo, a Deusa não é eliminada, mas absorvida e colocada em um novo relacionamento com Javé como seu Senhor. Além da transformação do matrimônio Sagrado, que passa de uma relação Deusa-rei para uma relação Deus patriarcal-esposa servidora, o javismo apropria-se das imagens femininas para caracterizar esse Deus masculino, como mãe, noiva, sábia, etc. Deste modo, se legitima o poder e controle masculino. 
A narrativa de $1 \mathrm{Rs} 11,1-13$, fiel à teologia deuteronomista e cuja possível redação final provém do período exílico, descreve que o principal motivo da sentença dada a Salomão por Javé foi seu contato com os cultos e divindades cananeias introduzidas pelas mulheres com as que Salomão se desposou.

Os cultos cananeus, além de estarem misturados ao culto a Javé, Deus único e ciumento que não tolera a presença de outros Deuses, fazem parte da constituição ampla e plural que caracteriza a religião dos israelitas no período de Salomão.

Perante longos séculos de sincretismo, os dirigentes javistas vão comprovando que os cultos "idolátricos", em que caem, sobretudo os varões, os marcados pela circuncisão, tem como aliado principal às mulheres "estrangeiras", seja pela prostituição sagrada, ou através da poligamia (Santos BENETTI, 1994, p. 81).

As mulheres foram culpadas de seduzir os homens e apartá-los do culto a Javé, e esse fato tem como ápice Salomão, o rei da sabedoria, aquele que tinha levado o prestígio de Israel a seu máximo grau, aquele que tinha construído um templo a Deus, aquele que foi abençoado com grandes riquezas, com um harém tão numeroso como seus copeiros, serventes e riquezas e que tinha construído um Templo com sacerdotes, sacrifícios e festas.

\section{SALOMÃO E SUA MUITAS MULHERES}

Salomão, casado com a filha do faraó do Egito, visitado e admirado pela rainha de Sabá, pouco a pouco foi ampliando seu harém com mulheres "estrangeiras" que levaram o reino a uma apostasia pública: um escândalo, uma tentação, um pecado que marca a fogo a história de Israel.

O texto 1Rs 11,1-13 desempenha um papel importante dentro da narrativa de Salomão, pois constituem a antessala de seu declínio. É importante porque, nestes versículos, os redatores fazem uma espécie de sumário da atividade de seu reinado, apresentando as principais causas que levaram a Javé a fazer um juízo contra o rei. Para uma maior compreensão dividimos o texto na seguinte estrutura: 
a) Salomão e as mulheres estrangeiras $(11,1-3)$

b) As mulheres de Salomão desviam seu coração $(11,4-8)$

c) Juízo de Deus sobre Salomão (11,9-13)

Esta delimitação leva em consideração o desenvolvimento narrativo do relato. Na primeira parte, se apresenta o problema: Salomão desposa a mulheres estrangeiras; no centro do relato, se apresenta o clímax da narrativa: são essas mulheres as causantes do desvio do coração do rei; finalmente, o final do relato apresenta a sentencia contra Salomão e sua descendência.

\section{MULHERES ESTRANGEIRAS NO HARÉM DE SALOMÃO}

E o rei Salomão amou muitas mulheres estrangeiras, além da filha do faraó: moabitas, amonitas, edomitas, sidônias e heteias das nações que havia dito Javé aos filhos de Israel, não ireis para eles e eles não venham a vós; eis que certamente desviarão vosso coração para seus deuses. Apegou-se Salomão com amor e houve para ele mulheres princesas setecentas e concubinas trezentas e desviaram suas mulheres seu coração (1Rs 11,1-3).

O autor apresenta três motivos óbvios para a condenação de Salomão. O primeiro é que o rei, além da filha do faraó, amou mulheres estrangeiras das nações que Javé havia proibido aos israelitas estabelecer relacionamento, devido ao perigo que estas representavam em levá-los a outros deuses. O segundo é a advertência do que esses relacionamentos desviariam seu coração para outros deuses. Como consequência das anteriores, o terceiro revela que Salomão apegou-se a elas por amor.

Ao que parece, não há problema relacionado ao número elevado de mulheres que Salomão amou, e sim com o fato de que estas o levaram até outros deuses. Percebe-se aqui como os textos androcêntricos encobrem os excessos de Salomão e o justificam pelo suposto amor proferido por ele. O verbo ahavá - "amar, gostar, agradar, encantar" - é frequentemente utilizado para justificar a poligamia dos patriarcas que gozam de uma posição promitente dentro da história, como se evidencia nos casos dos patriarcas Abraão, Isaac, Elcaná, etc. Assim, toda a culpa recai sobre estas mulheres e não sobre o pobre Salomão, que simplesmente amou. A compra e venda de mulheres na antiguidade 
era legitimada e bem vista por Deus, pois, afinal de contas, as riquezas atesouradas por Salomão se derivam destas alianças com mulheres estrangeiras.

Salomão amou mulheres de Moab, um povo situado ao leste do Mar Morto e cuja origem se remonta à Idade de Bronze Recente. Este território pese a ser conquistado pela tribo de Rubem, manteve sua independência por um longo período até ser conquistado pelos assírios ao redor do ano 732 a.C. (Antonio PÉREZ LAGARCHA, 2003). Sua religião era politeísta, suas principais deidades eram Quemós e Ashar. Amou também mulheres de Ammon, localidade situada ao norte de Moab entre o deserto de Síria, o rio Jordao e os rios Jabok e Armon, que foram submetidos pelos israelitas ao redor do século $X$ a.C., até 0721 época da invasão Asíria. Adoraram principalmente a Milcom. Da região do Sul de Judeia, provinham as mulheres edomitas e também Esaú, o irmão de Jacó, com quem se disputou a primogenitura. Da região costeira do mar Mediterrâneo provêm as mulheres sidonias, cidade fenícia cuja origem se remonta ao terceiro milênio até sua destruição pelos assírios por volta do 677 a.C. Os cultos canaanitas a Baal e Astarte também se praticaram nesta região. Da região dos Hititas, as heteias, povos que remontam ao século XVIII a.C. e cuja desaparição se dá com as invasões dos povos do mar, isto é, os filisteus, por volta do 1.200 a.C.

Salomão desviou seu coração leb, o órgão do discernimento, o mesmo órgão ao que Javé lhe teria insuflado de justiça e discernimento para julgar entre o bem e o mal, aquele mesmo coração que lhe teria favorecido com ouro e riquezas. Um tema central que atravessa todo o ciclo de relatos sobre Salomão é, justamente, a relação entre a conduta do rei perante os problemas cotidianos do povo. Ainda que esta conexão seja quebrada pelo monarca, a relação entre a conduta justa e o Estado continua. A busca de uma ordem no mundo criado por Deus e a possibilidade poder viver sábia e honestamente neste mundo (cf. 1 Rs 10,9$)$ continua. Ao menos, isto é o que se deduz da sentencia final, na qual Javé promete uma tribo aos descendentes de Davi por conta da cidade de Jerusalém (v.13). 


\section{AS MULHERES DE SALOMÃO DESVIAM SEU CORAÇÃO}

E sucedeu em tempo da velhice de Salomão suas mulheres desviaram seu coração traz outros deuses e não esteve seu coração inteiro com Javé seu Deus como o coração de Davi seu pai. E caminhou Salomão trás Astarte deus dos sidônios e Milcom abominação de amonitas. E fez Salomão o mal ao olhos de Javé e não foi integro traz Javé como Davi seu pai. Então construiu Salomão um lugar alto a Quemós, abominação de Moab na montanha que fica em frente de Jerusalém e a Moleque abominação dos filhos de Amom. E assim fez a todas suas mulheres estrangeiras, as quais queimavam incenso e ofereciam sacrifícios a seus deuses (1Rs 11,1-8).

No início da narrativa, Salomão é apresentado como possuidor de um coração sábio, ou seja, justo e reto aos olhos de Javé. Porém, ele não permaneceu assim devido às mulheres. Elas foram as culpáveis do desvio do coração deste homem justo, o mais justo do qual se tenha notícia. Este parece ser o consenso não somente da maioria dos intérpretes destes versículos, que colocaram Davi como o rei exemplar e fundamentaram os pecados de Salomão nos seus relacionamentos e nos desvios em direção a outros deuses. Afinal, Javé é um Deus ciumento. A ele, e somente a ele, deve-se amar. Porém, por detrás desse amor se escondem as dinâmicas de poder, de despojo e saqueio de povos inteiros com suas tradições religiosas. A dinâmica é clara: eu te dou os tesouros das outras nações se você permanecer fiel ao meu amor.

\section{JUÍZO DE DEUS SOBRE SALOMÃO}

E irou-se Javé com Salomão, porquanto desviara seu coração do Javé, Deus de Israel, que se tinha revelado a ele duas vezes. E tinha mandado a ele sobre este assunto não caminhar traz outros deuses e não guardou o que tinha mandado Javé. E disse Javé a Salomão: "a causa de que aconteceu isto contigo e não ter guardado minha aliança e meus preceitos que ordenei sobre ti, arrancar, arrancarei o reino de junto de ti e o darei a um dos seus servos. No entanto, em teus dias não farei isso, por causa de teu Pai Davi da mão de teu filho o arrancarei. Não tirarei dele todo o reino, arrancarei uma tribo e a darei a teu filho por causa de David meu servo y a causa de Jerusalém, a cidade que escolhi" (1 Reis 11:9-13). 
O texto revela os motivos pelos quais Javé se irou contra Salomão: este desviou seu coração do Deus que se Ihe havia revelado em duas oportunidades e, como consequência disto, teria rompido sua aliança e abandonado seus preceitos.

Este texto revela três elementos importantes: o primeiro é o fato de que os cultos de outros deuses e deusas se realizam em paralelo com o culto a Javé, o Deus único que não admite a presença de outros Deuses; o segundo elemento aponta para o fato de que estes cultos provêm, justamente, dos povos conquistados e de outros vizinhos com quem Salomão fez alianças; por fim, o terceiro é o fato de que a apostasia é provocada fundamentalmente pelas mulheres estrangeiras que seduzem e tentam o rei, mudando seu coração e pervertendo-o.

Definitivamente, o redator apresenta uma culpada: a mulher. Como o javismo não possui uma mitologia rica e total que explicasse os fenômenos da natureza, origem da vida e do mundo, o matrimônio, o parto e a morte, se combate a cultura cananeia com os mesmos elementos que fundamenta sua religião: mitos, símbolos femininos, sexualidade. $O$ javismo centralizador do templo de Jerusalém está apoiado nos varões, elas não necessitam do templo pois possuem seus próprios altares. Caso contrário, sucede com as mulheres israelitas que, sim, eram obrigadas e seu lugar no culto é no átrio, isto é, a extramuros do templo.

Evidencias bíblicas e extra bíblicas atestam que muitas mulheres israelitas e principalmente estrangeiras ocuparam lugares importantes, foram sacerdotisas, rainhas mães, profetas, enfim, pessoas influentes nas decisões dos reis e nas cortes e participaram ativamente nos rituais religiosos.

Assim, o grande harém de Salomão, que o posicionara, a princípio, num lugar privilegiado de realizações administrativas, políticas e religiosas, bem como na construção de seu palácio e do majestoso templo de Javé, é o mesmo harém que mais tarde é acusado de levá-lo à ruína e à sua desintegração. Tendo em vista esta ideologia, o sacerdote Esdras faz com que estas mulheres estrangeiras se tornem muito perigosas para a reconstrução do povo de Deus. Desde modo, o monoteísmo patriarcal é construído sob o medo das mulheres estrangeiras, representantes do politeísmo e da adoração às deusas. É a luta do Deus único, patriarcal, masculino contra a riqueza politeísta das deusas. 


\section{ASTARTE DOS SIDÔNIOS}

Axoret é o nome dado à Deusa cananeia comumente conhecida como Astarte. Ela é a Deusa do amor e da fertilidade, é a Grande Deusa, a Rainha do Céu e Mãe de todas as deidades. Astarte era venerada com símbolos sexuais femininos: Deusa nua que mostrava seus signos específicos, peitos e genitálias. Entre os cananeus, simbolizou a procriação feminina e também a sabedoria. A Deusa Astarte é bem conhecida no ocidente semita, no Ugaritico (Cyrus GORDON, 1967) e em outras partes, como no Egito (Samuel DRIVER, 1966). As inscrições fenícias, tanto como as numerosas figuras femininas de deidades descobertas na Palestina, provam que Astarte foi venerada proeminentemente na Palestina e no sul da Síria (James PRITCHARD, 1954).

Estudiosos concordam que a Astarte mencionada na Bíblia Hebraica é esta Deusa, mas nos textos bíblicos a forma Axtoret é alterada pelo plural Axtarot. O termo Ashtoreth aparece nove vezes na Bíblia Hebraica, referindo-se a uma Deusa. Três destas ocorrências aparecem no singular Axtoret (1Rs 11,5 e 33; 2Re 23,13). As outras seis vezes estão no plural Axtarot (Jz 2,13; 10,6; $1 \mathrm{Sm} \mathrm{7,3} \mathrm{e} \mathrm{4;} \mathrm{12,10;} \mathrm{31,10).} \mathrm{O} \mathrm{termo} \mathrm{é} \mathrm{registrado}$ também três vezes no livro do Deuteronômio ( $D t 7,13 ; 28,4 ; 18,51$ ). O exame completo destas passagens não é tema deste estudo, ainda que com isso seja possível evidenciar que todas as referências a Astarte na Bíblia Hebraica se dão no contexto da história deuteronomista e, na maioria das vezes, é identificada como uma deidade estrangeira dentro de contextos polêmicos.

É interessante notar ainda que nos textos paralelos de Crônicas se evita qualquer alusão a Astarte, parecendo mesmo que essa deidade sequer existisse no Israel Antigo. Contudo, o culto a Astarte continua ainda no mundo greco-romano. No entanto, parece que os cronistas não acharam esta Deusa importante para a história israelita.

Apesar do tratamento polêmico e negativo dado a Astarte na história deuteronomista, ainda é possível identificar o que realmente há por trás destas referências. O nome Astarte, no livro do Deuteronômio, é relacionado com os temas da fertilidade da terra e dos animais 'shtrt ts'nd - "cordeiros e rebanhos". Sua importância é reduzida a suas funções, distanciando-se de qualquer identificação como divindade. Por 
isso, é interessante se perguntar pela hipóstase do nome da divindade: será que a deidade veio primeiro e o nome depois? Para Mathias Delcor (1974), os atestados cronológicos ratificam que a deidade veio primeiro, antes do idioma. Assim, percebe-se que o processo de despersonalização e desdivinização das deidades é intencional para os redatores deuteronomistas, pois é evidente que estas deidades já eram bem conhecidas em uma grande área da Palestina. Nesse processo de despersonificação, Astarte passou de ser uma deidade famosa e adorada em Israel e Judá para se transformar numa abstração da fertilidade do idioma hebraico.

Evidentemente, esta intencionalidade é produto fruto de uma produção literária exílica, porém, estas divindades aludem a experiências religiosas históricas, cujas práticas eram legítimas nas ruas de Jerusalém e Judá. Por exemplo, no livro de Jeremias, fala-se da "Rainha do Céu" (Jr 44,16) (Maricel MENA-LÓPEZ, 2008), um título similar à divindade semita Astarte. Muitos estudiosos apontam semelhanças com outras divindades estrangeiras como Istar de Mesopotâmia, Asherá e Anat junto a outras.

A Deusa Istar de Mesopotâmia era diretora de pessoas, profetisa, dama de visão. Nos arquivos arqueológicos da cidade de Nimrud, onde Istar era adorada, revelaram que as mulheres desempenhavam papéis de juízas e magistradas nas cortes de justiça (Merlin STONE, 1994). Mas o interessante é que a adoração a divindades estrangeiras é um fato conhecido inclusive antes da época dos reis de Israel e Judá.

As evidências tardias apresentam uma estreita relação entre Astarte e Baal. Ambas são divindades guerreiras que sugerem uma relação marital. Sugerem ainda que ela seria uma rainha que atuou em consórcio com o rei Baal. A designação da Deusa Astarte, bem como seu caráter matrimonial e sua especial relação com o Deus guerreiro Baal, se aproxima ao caráter matrimonial do Deus guerreiro Javé com a Deusa Asherá.

Os textos semitas ocidentais comprovaram que a hipóstase do nome da deidade israelita originariamente pode ter sido associada a uma Deusa da primitiva religião israelita. As evidências bíblicas também sugerem influências semitas ocidentais para o nome de hipóstase. A colocação deste nome em fontes israelitas representa "uma presença cultual” (P. Kyle MCCARTER JR, 1987). As evidências bíblicas sugeririam 
uma colocação litúrgica mais antiga do que a da Deusa semita ocidental. Apesar do caráter problemático de tal evidência, no Taanac aparecem testemunhos bíblicos da Deusa. Algumas das polêmicas contra o impacto de uma Deusa nas figuras bíblicas são resolvidas ao estudar a hipóstase da sabedoria de Asherá e Astarte dentro a Idade de Ferro israelita.

As Deusas Asherá e Astarte também foram Deusas no Israel desde a Idade de Ferro. O impacto destas deidades sobre a religião de Israel baseia-se na introdução da sabedoria que mais tarde é personificada na hokmah israelita. As inscrições que contêm Isrth de yhwh querem se acomodar ao modelo monoteísta javista que vai contra as outras deidades que atuaram também no seio israelita. Sugere-se ainda que os santuários a Astarte foram um grande centro de culto a Deuses similares ao Deus Javé com quem ela trabalharia em sociedade durante a monarquia israelita.

Axtoret, a depreciada deidade pagã do Antigo Testamento é, apesar dos esforços dos escribas bíblicos por disfarçar sua identidade, a Grande Deusa, como se conhecia em Canaã e Sabá, a rainha do Céu no Oriente Próximo. Aqueles adoradores pagãos de ídolos na Bíblia haviam estado rezando-lhe a uma Deusa ( Jz 2,13; Jz 10,6; 1Rs 11,5; 1Rs 11,33), que é conhecida em outros lugares como: Nana, Nut, Anat, Anahita, Istar, Au Set, Ishara, Asherá, Astar, Atar, Hatór e Shayba, a divina antepassada de muitos nomes.

\section{ISTHAR-QUEMÓS DOS MOABITAS}

Outro deus nomeado em 1Rs 11 é o deus Quemós (em hebreu kemos, Nm 21,29; Jz 11,24; 1Rs 11,7.33; 2Rs 23,13; Jr 48,7.13.46), e é interessante seu estudo pelo fato que sua atuação está descrita em parceria com a deusa Istar. Este deus é conhecido como a deidade nacional dos moabitas. Ele aparece na lista de deuses de Tell Mardikh, antigo Ebla, cidade estado da Síria, nos arquivos reais datados do 2600-2250 a.C. Este deus, além de ser reconhecido como uma das 500 deidades de Elba, foi considerado como um dos deuses principais desta cidade (Gerald MATTINGLY, 1987), já que havia um templo em Elba para ele. Quemós era também o nome de um recipiente para as oferendas.

Os dados existentes que nos permitem reconstruir a religião dos moabitas procedem de dois tipos de fontes: textual e arqueológica. Na- 
turalmente, muitos dos dados arqueológicos estão sujeitos a uma longa gama de interpretações e de incertezas nas conclusões. As fontes mais importantes de informação sobre a religião dos moabitas são o Antigo Testamento e a inscrição da Mesha (Daniel BLOCK, 2013). Embora os escritos hebraicos sejam críticos com a religião de Moab, esta referência não deve ser ignorada. Os textos bíblicos reconhecem a Quemós como a deidade nacional dos moabitas assim como a existência de um culto para este deus similar ao culto de Javé, sendo ainda este deus o principal rival da fé dos israelitas (confira Nm 22,29; Jz 11,24; 1Rs 11,7; 11,33; 2Rs 23,13; Jr 48,7. 13. 46).

Indubitavelmente, a fonte mais importante para o estudo da religião moabita é a inscrição de Mesha, texto que foi escrito por volta do ano 830 a.C. Esta inscrição celebra o triunfo de Moab sobre Israel. Esta vitória é atribuída a Quemós, a deidade principal deste povo.

Na Mesha encontra-se informação sobre a natureza e a função do deus Quemós. Nela descreve-se o caráter bélico desta deidade. Trata-se, então, do deus da guerra. O nome composto Isthar-Quemós (linha 17) tem sugerido muitas interpretações. Entre elas, a mais convincente é que este deus atuou em consórcio com uma deidade feminina. Vários estudiosos sugerem que Ishtar-Quemós é o nome da cônjuge de Quemós. Esta deusa foi considerada a contraparte feminina de Quemós. Istar-Quemós foi associada a Istar ou Astarte. Entre outras evidências que apoiam esta interpretação, temos uma inscrição em aramaico de Kerak, datada do período helenístico.

Além dos elementos bíblicos e extra bíblicos, há várias representações artísticas que se relacionam com esta deidade. Algumas estatuetas humanas achadas em Moab foram identificadas com Quamós e, muito provavelmente, se tratam de representações artísticas do deus nacional de Moab (Łukasz TOBOŁA, 2013).

\section{RELIGIÃO E DEIDADES EM ISRAEL - ALGUMAS OBSERVAÇÕES}

$O$ impacto das deidades femininas na religião de Israel nos remete eminentemente ao estudo da Grande Deusa. As evidências arqueológicas provaram que a religião existiu e floresceu no Antigo e Médio Oriente milhões de anos antes da chegada do patriarca Abraão, primeiro profeta 
da deidade masculina Javé (Gn 17,5). A adoração à Deusa foi rastreada pelos antropólogos em comunidades neolíticas ao redor de 7000 a.C. e em algumas do paleolítico superior, de aproximadamente 25.000 a.C. Desde as origens do neolítico, sua existência foi certificada reiteradas vezes até tempos bem avançados como a época dos romanos. No entanto, os investigadores bíblicos afirmam que foi em um período tardio, entre 1800 e 1550 a.C., quando Abraão viveu em Canaã (Palestina).

Os autores deuteronomistas, fiéis a sua teologia em tono a um único Deus, um único povo, um único templo, condenaram os cultos e deidades estrangeiras até o ponto de convertê-las num totem ou objeto, tal como acontece no caso das deusas Asherá e Astarte. As passagens da Bíblia Hebraica que mencionam estas divindades são bastante condenatórias, mas testificam sua existência.

Todavia, os livros dos Reis revelam essa dinâmica entre a fé exclusiva de Javé e a pluralidade religiosa popular da vida familiar do povo israelita na esfera estatal. As reformas de Ezequias (2Rs 18,3-4) e Josias (2Rs 23,4-14), bem como diversos relatos de Reis que inseriram a Deusa no templo, por exemplo Manassés (2Rs 21,3-7), indicam a presença de Asherah no templo de Jerusalém, e também a presença de outros Deuses (Sue'Hellen MATOS, 2019, p. 354).

A reforma religiosa do tempo de Josias, ao tentar erradicar a adoração da deusa Asherá, por exemplo, reduz sua imagem a uma estatueta de madeira. Mas durante os séculos anteriores a esta reforma, como é demonstrado amplamente nos achados de Taanach, o Ajruf de Kuntillet e Khirbet el-Qom, Asherá aparece intimamente emparelhada com Javé. Além disso, no século oitavo a.C., os profetas não condenaram a Asherá. A adoração tanto de Asherá como de Astarte era totalmente aceitável antes do movimento da reforma de Josias.

Neste breve percurso histórico, pude perceber a enorme distância que há entre as imagens contemporâneas e as atitudes pré-históricas mais antigas com respeito às capacidades racionais e intelectuais da mulher, já que na antiguidade a Deusa foi reverenciada como conseIheira, sábia e profetisa. 
Assim sendo, as mulheres da corte de Salomão alcançaram um papel proeminente na vida cultural e política israelita, ainda que, com a monarquia, sua liderança tenha sido estereotipada nos papéis de pecadoras ou esposa dóceis, e pouco a pouco tenham deixado de participar da circulação do poder.

A sexualidade era vivida tanto nos antigos cananeus, como pelos babilônios, egípcios, sabeus, etc., como algo sagrado já que era parte do culto às Deusas e Deuses. Agora, na ideologia bíblica exílica e pós-exílica, a sexualidade é completamente dessacralizada e é apresentada como um simples objeto manipulável por um Deus único e não sexuado. Para os israelitas, o corpo sexuado passa a ser um componente a mais da criação, como o trabalho e toda a cultura. O sagrado pertence a outra esfera, é somente Deus e aquilo que ele consagrou, por exemplo, o templo, o altar, as oferendas, o sacrifício. Deste modo, a sacralidade do corpo feminino lhe foi roubada, pois o sagrado passou a ser algo distinto, diferente, próprio da esfera divina. Algo tão cotidiano como o sexo não tem essa característica.

Certo é que o perigo do politeísmo foi suficientemente forte para que a Bíblia e o judaísmo preferissem deixar a sexualidade a certa distância, pois, já eram muitos os problemas que ocasionava ao javismo. Ainda que Salomão e seus sucessores incorporassem cultos sexuais, inclusive dentro do mesmo templo a Javé em Jerusalém, não pareceu conveniente nenhum tipo de integração sexual no culto mosaico. Por isso, era melhor mostrar uma posição radical. Inclusive, o Matrimônio Sagrado, tão comum nos cultos cananeus, passou a ser para os israelitas uma metáfora de exclusividade, de dedicação e lealdade ao marido. $O$ Deus revelado na imagem do marido ameaçador é aquele com quem Israel conveniava e estava desejando imitar (Renita WEEMS, 1997).

A antiga apreensão da Deusa como Matriz Primordial nunca desapareceu da imaginação religiosa humana, apesar da superposição do monoteísmo masculino. Ela sobreviveu na metáfora do divino. Em um primeiro momento foi emparelhada com uma divindade masculina. Nesse processo, o Matrimônio Sagrado Deusa-Deus passa de uma relação Deusa-rei para uma relação Deus patriarcal-esposa servidora. Em outro momento, o javismo apropria-se de imagens femininas de Deus, sendo 
que as imagens patriarcais masculinas eram limitadas demais para representar a variedade de relacionamentos da divindade com Israel que o pensamento hebraico desejava expressar.

Em suma, pode-se dizer que Israel, sob o domínio de Salomão, se constitui como um centro político e cultural onde confluem diferentes grupos e culturas, fazendo de Israel um grande centro cosmopolita. Esta abertura não se dá somente por meio da exploração da mão de obra estrangeira e das relações políticas e comerciais com outros povos e nações, mas, também, pela influência que as culturas e religiões das deusas exerceram na corte de Salomão. Com esta proposição, o convite ainda é pela necessidade de descentralização do poder, do ser, do saber camuflado em discursos religiosos monolíticos que escondem a riqueza e a diversidade. Quem sabe isto nos ajude a abrir nossas mãos e abraçar a diferença para além dos fundamentalismos e fanatismos religiosos que se fundamentam na negação daqueles que tem formas distintas de manifestações do divino.

\section{REFERÊNCIAS}

BATISTA, Keila Fernandes. O debate historiográfico acerca da ideia da "prostituição sagrada” no antigo crescente fértil. Revista Vernáculo, n. 28, 2011, pp. 187-213.

BENETTI, Santos. Sexualidad y erotismo en la Biblia, São Paulo, 1994.

BLOCK, Daniel. The Gods of the Nations: A Study in Ancient Near Eastern Nacional Theology. Eugene: Wipf and Stock Publishers, 2013.

DELCOR, Mathias. Astarté et la fécondité des troupeaux en Deut. 7,13 et paralleles. Ugarit-Forschungen, v. 6, 1974, pp. 7-14.

DEVER, William G. Israelite Woman as "Ritual Experts": Orthodoxy or Orthopraxis? In: ACKERMAN, Susan; CARTER, Harles E.; NAKHAI, Beth Alpert (Eds.). Celebrate Her for the Fruit of Her Hands: Essays in Honor of Carol L. Meyers. Winona Lake: Eisenbrauns, 2015, pp. 187-203.

DRIVER, Samuel Rolles. Notes on the Hebrew Text and the Topography of the Book of Samuel. Oxford: Clarendon Press, 1966.

FINKELSTEIN, Israel. O Reino esquecido: Arqueologia e História de Israel Norte. São Paulo: Paulus, 2015.

FRAZER, James; MEAD, Margaret. Sex and Temperament in Three Primitive Societies. Nova Iorque: William Morrow \& Company, 1935.

GIMBUTAS, Marija. El lenguaje de la Diosa. Oviedo: Grupo Editorial, 1996. 
GORDON, Cyrus H. Ugaritic Textbook. Roma: Editrice Pontificio Istituto Biblico, 1967. HADLEY, Judith. M. Yahweh and 'His Asherah': Archeological and Textual Evidence for the Cult of the Goddess. In: DIETRICH, Walter; KLOPFENSTEIN, Martin A. (Eds.). Ein Gott allein? JHWH-Verherung und biblicher Monotheismus im Kontext der israelitischen und altorientalischen Religiongeschichte. Friburgo: Editions Universitaries / Göttingen, Vandenhoeck \& Ruprecht, 1994, pp. 235-268.

HAWKES, Jacketta. Dawn of The Gods: With Photographs by Dimitrios Harrisiads and others illustrations. Londres: Chatto \& Windos, 1958.

JAMES, Edwin Oliver. The Ancient Gods - The History and Diffusion of Religion in the Ancient Near East and the Eastern Mediterranean. Londres: Weidenfeld \& Nicolson, 1960.

MATOS, Sue'Hellen Monteiro de. A influência das deusas Asherah e Ishtar na construção da imagem materna de Javé em Dêutero-Isaías. Âncora - Revista Digital de Estudos de Religião, v. IX, ano 9, 2014, s/n.

MATTINGLY, Gerald L. Chemosh. In: FREEDMAN, David Noel (Ed.). The Anchor Bible Dictionary - Volume 1. Nova lorque: Doubleday, 1987, pp. 895-897.

MCCARTER JR, P. Kyle. Aspects of the Religion of the Israelite Monarchy - Biblical and Epigraphic Data. In: MILLER, Patrick D.; HANSON, Paul D.; MCDRIDE, S. Dean (Eds.). Ancient Israelite Religion. Filadélfia: Fortress Press, 1987, pp. 137-155.

MENA-LÓPEZ, Maricel. Resistencia femenina y religión popular - una aproximación a partir de Jr 44,15-19. Sentires Teológicos En Perspectiva Liberadora. Bogotá: Sello Editorial Javeriano, 2008, p. 93-109.

PÉREZ LARGACHA, Antonio (2003). El Mediterráneo Oriental ante la llegada de los Pueblos del Mar. Gerión - Revista de Historia Antigua, v. 21, n. 1, 2003, p. 27-49.

PICAZA, Xabier. Mujeres de la Biblia Judía. Barcelona: CLIE, 2013.

PLASKOW, Jusith. Standing Again at Sinai: Judaism from a Feminist Perspective. Nova lorque: HarperCollins, 1991.

PRITCHARD, James Bennett (Ed.). The Ancient Near East in Pictures Relating to the Old Testament. Nova Jersey: Princeton University Press, 1954.

REIMER, Haroldo. Monoteísmo e identidade. In: REIMER, Ivone Richter (Org.). Imaginários da divindade. Goiânia: Ed. da UCG, 2008, pp. 9-24.

RUETHER, Rosemary R. Sexismo e religião. São Leopoldo: Sinodal, 1993.

SANTIAGO, Fydel Sousa. Deuses e Deusas na formação cultural de Israel. Periódico de Cadernos de Resumos e Anais da Faculdade Unida de Vitória, v. 4 n. 2, 2014, pp. 70-73. STONE, Merlin, Cuando Dios era Mujer. In: RESS, Mary Judith; SEIBART-CUADRA, Ute; SJORUP, Lene (Eds.). Del Cielo a la Tierra - Una antología de Teología Feminista. Santiago: Sello Azul Editorial de Mujeres, 1994, p.175-184. 
TOBOŁA, Łukasz. The divine name Chemosh: a new etymological proposal. Biblica, v. 94, n. 4, 2013, p. 573-575.

WEEMS, Renita J. Amor maltratado - Matrimonio, sexo y violencia en los profetas hebreos. Bilbao: Editora Desclée De Brouwer, 1997.

Submetido em: 12-8-2021

Aceito em: 12-11-2021 